\section{Investigation of Disease Resistance and Cold Tolerance of Solanum lycopersicoides for Tomato Improvement}

\author{
Lingxia Zhao ${ }^{1}$ and Chengxiang Qiu ${ }^{2}$ \\ Plant Biotechnology Research Center, School of Agriculture and Biology, \\ Fudan-SJTU-Nottingham Plant Biotechnology R\&D Center, Shanghai Jiao \\ Tong University, 1954 Huashan Road, Shanghai 200030, China

\section{Jingfu Li} \\ School of Horticulture, Northeast Agricultural University, 59 Muchai Road, \\ Haerbin 150030, China
}

\author{
Yourong Chai \\ State Key Laboratory of Genetic Engineering, School of Life Sciences, Fudan- \\ SJTU-Nottingham Plant Biotechnology R\&D Center, Fudan University, 220 \\ Handan Road, Shanghai 200433, China
}

\section{Guoyin Kai and Zhugang Li}

Plant Biotechnology Research Center, School of Agriculture and Biology, Fudan-SJTU-Nottingham Plant Biotechnology R\&D Center, Shanghai Jiao Tong University, 1954 Huashan Road, Shanghai 200030, China

\section{Xiaofen Sun}

State Key Laboratory of Genetic Engineering, School of Life Sciences, FudanSJTU-Nottingham Plant Biotechnology R\&D Center, Fudan University, 220 Handan Road, Shanghai 200433, China

\section{K.X. Tang ${ }^{3}$}

Plant Biotechnology Research Center, School of Agriculture and Biology, Fudan-SJTU-Nottingham Plant Biotechnology R\&D Center, Shanghai Jiao Tong University, 1954 Huashan Road, Shanghai 200030, China

\section{Additional index words. cold tolerance, disease resistance, Solanum lycopersicoides}

\begin{abstract}
Solanum lycopersicoides is a valuable genetic resource for tomato (Lycopersicon esculentum) genetic improvement. However, there are few reports on its agronomic traits such as disease resistance and cold tolerance. In this paper, the resistance to cucumber mosaic virus (CMV) and leaf mold (Cladosporium fulvum Cooke) and cold tolerance of five lines of $S$. lycopersicoides were studied through investigation of disease inoculation and electrolyte leakage analysis. The results showed that $S$. lycopersicoides was highly resistant or immune to $\mathrm{CMV}$ and leaf mold and more tolerant to low temperature than $L$. esculentum. This study is helpful for the genetic improvement of tomato by using $S$. lycopersicoides as breeding materials.
\end{abstract}

\footnotetext{
Received for publication 31 Jan. 2004. Accepted for publication 20 June 2004. We thank Chetelat (TGRC) for kindly providing seeds of $S$. lycopersicoides. This research was funded by the Ministry of Education, China.

${ }^{1}$ Co-first author. Also affiliated with State Key Laboratory of Genetic Engineering, School of Life Sciences, Fudan-SJTU-Nottingham Plant Biotechnology R\&D Center, Fudan University, 220 Handan Road, Shanghai 200433, China, and School of Horticulture, Northeast Agricultural University, 59 Muchai Road, Haerbin 150030, China.

${ }^{2}$ Co-first author.

${ }^{3}$ Also affiliated with State Key Laboratory of Genetic Engineering, School of Life Sciences, Fudan-SJTUNottingham Plant Biotechnology R\&D Center, Fudan University, 220 Handan Road, Shanghai 200433, China. Corresponding author; e-mail kxtang1@yahoo.com or kxtang@sjtu.edu.cn.
}

Lack of genetic variability is cutre a major problem for tomato (Lycopersicon esculentum) breeding, which was attributed to two major factors: 1) genetic variability of the tomato's ancestor ( $L$. esculentum var. cerasiforme) was lost during migration from its originating region (Andean area through northern South America) to Mesoamerica, and 2) self-pollination coupled with long periods of domestication and modern breeding (Chetelat et al., 1997; Rick, 1988; Rick and Chetelat, 1995; Rick and Holle, 1990). Hence, some necessary breeding materials such as those resistant or tolerant to cucumber mosaic virus (CMV) and cold temperatures are lacking. Despite genes resistant to some strains of Cladosporium fulvum Cooke ex- ist in Lycopersicon such as L. esculentum, L. peruviamum Mill., L. chilens Dun., and L.pimpinellifolium Mill., numerous strains and quick variation of $C$. fulvum could eliminate the resistance of the cultivated varieties $(\mathrm{Li}$, 1995; Rick and Chetelat, 1995; Zhang et al., 2000). Consequently, it is necessary to find much more resistance resources to $C$. fulvum for tomato improvement.

Solanum lycopersicoides Dun. $(2 \mathrm{n}=2 \mathrm{x}$ $=24$ ), originating from the west Andes area along the Chile-Peru border, is a close wild relative of tomato (Lycopersicon esculentum Mill.). It is the only species in genus Solanum that can cross with $L$. esculentum. Hence, $S$. lycopersicoides has attracted tomato breeders' attention due to its excellent tolerance to abiotic stresses, such as cold and infertility, and its resistance or tolerance to several diseases, such as tomato mosaic virus, phytophthora root rot (Phytophthora parasitica Dast.), and gray mold (Botrytis cinerea pers. ex Fr.) (Chetelat et al., 1997, 1998; Hossain et al., 1994; Kamps et al., 1987; Rick, 1951; Rick and Chetelat, 1995; Rick et al., 1988; Wolf et al., 1986).

Using S. lycopersicoides as breeding material for genetic improvement of tomato, Rick obtained an intergeneric hybrid [F LS], but the hybrid could not be backcrossed directly to L. esculentum as neither the staminate parent, due to its pollen sterility, nor the pistillate parent, due to its unilateral incompatibility (Rick, 1951). Therefore, during the last halfcentury, the research on $S$. lycopersicoides has mainly focused on how to obtain fertile intergeneric hybrid between $S$. lycopersicoides and L.esculentum (Chetelat and Meglic, 2000; Chetelat et al., 1989, 1997, 1998, 2000; Guri et al., 1991; Handley et al., 1986; Hossain et al., 1994; Matsumoto et al., 1997; Rick, 1986; Rick et al., 1986). Fertile intergeneric hybrids between $S$. lycopersicoides and L. esculentum were recently obtained by both sexual and asexual means (Chetelat and Meglic, 2000; Chelelat et al., 1997; Matsumoto et al., 1997). This progress is a milestone in genetic improvement of tomato because it successfully uses $S$. lycopersicoides as breeding material.

Presently, there are few detailed reports on abiotic stress tolerance and disease resistance of S. lycopersicoides, though these agronomic traits are very important for tomato genetic improvement. In present study, several lines of S. lycopersicoides were evaluated for resistance to CMV and leaf mold, and tolerance to cold stress.

$$
\text { to cold stress. }
$$

\section{Materials and Methods}

Plant materials. Five lines of S. lycopersicoides (LA1990, LA2386, LA2730, LA2776, and LA2951) and two lines of Lycopersicon (L.esculentum 'UC82B' and 'Zaofen No. 2') were used in the present study. The five lines of S. lycopersicoides were kindly provided by R.T. Chetelat from the C.M. Rick of Tomato Genetic Resources Center at the University of California-Davis, while L.esculentum cultivars UC82B and Zaofen No.2 were obtained from the School of Horticulture, Northeast Agricultural University, China. 
Pathogen inoculation. CMV (severe mosaic strain) and leaf mold (C. fulvum strain 1.2.3) were obtained from the School of Horticulture, Northeast Agricultural University, China. Inoculation, disease scoring, and statistical analysis of CMV and leaf mold resistances of S. Lycopersicoides, including all the five lines, were carried out using the method described by $\mathrm{Li}$ (1995).

CMV was maintained in tobacco (Nicotiana tabacum 'Samsun') and propagated using sensitive 'Zaofen No. 2 ' under $28^{\circ} \mathrm{C}$ for $10 \mathrm{~d}$. Ten-day-old leaves infected by CMV were collected and homogenized with $8 \mathrm{~mL}$ phosphate buffer $\left(\mathrm{pH}=8.0,0.03 \mathrm{~mol} \cdot \mathrm{L}^{-1}\right)$ per gram of tissue, and then centrifuged for $15 \mathrm{~min}$ at 3000 $\mathrm{rpm} / \mathrm{min}$. Supernatant (containing CMV) was collected, then quartz sands were added to it to increase wounding of leaves. Sterile cotton swabs were used to uniformly apply, with slight pressure, the supernatant-quartz sands mixture onto the whole surface of the tested materials. Inoculations were repeated on the third day. Three- or four-euphylla-old plantlets were used for inoculation. Investigation time was at 21 , 28,35 , and $42 \mathrm{~d}$, respectively.

Leafmold (C. fulvum strain 1.2.3) was propagated on potato dextrose agar (PDA) medium, and diluted to $10^{6}$ spores $/ \mathrm{mL}$ suspension solution with sterile distilled water for inoculation. Leaf mold solution was sprayed uniformly on back of leaves using a sprayer (low flow) under 22 to 25 ${ }^{\circ} \mathrm{C}$ with $>90 \%$ relative humidity. Five- or sixeuphylla-old plantlets were used for inoculation. Investigation time was at 14 and $21 \mathrm{~d}$.

Each disease treatment experiment was repeated three times and six plants were investigated in each replicate, while 'Zaofen No. 2' tomato was used as the susceptible control.

Disease index and infection percentage were calculated using two different formulae: 1) disease index $=\sum$ (disease grade $\times$ plant number of each grade)/highest disease grade $x$ inoculated plant number) and

2) infection percentage $=$ (infected number/ total inoculated number) $\times 100 \%$

Cold tolerance: Experiment 1. To determine a non-damaging temperature and appropriate cold treatment duration on $L$. esculentum 'UC82B', a cold-tolerant tomato line, three levels of low-temperature intensity [(day 6 ${ }^{\circ} \mathrm{C} /$ night $2{ }^{\circ} \mathrm{C}$ ), (day $14^{\circ} \mathrm{C} /$ night $10^{\circ} \mathrm{C}$ ) and (day $25^{\circ} \mathrm{C} /$ night $15^{\circ} \mathrm{C}$ )] and six levels of treatment duration $(24,48,72,96,120$, and $144 \mathrm{~h})$ were applied. The treatments were repeated three times with each replication using six plants.

Coldtolerance: Experiment 2. Todetermine cold tolerance of $S$. lycopersicoides, plants with six to seven leaves from the five lines of $S$. lycopersicoides (LA1990, LA2386, LA2730, LA2776, and LA2951) and L. esculentum 'UC82B' were treated with day $6^{\circ} \mathrm{C} /$ night 2 ${ }^{\circ} \mathrm{C}$ and day $25^{\circ} \mathrm{C} /$ night $15^{\circ} \mathrm{C}$ for $72 \mathrm{~h}$. These treatments were repeated three times with each replicate using six plants. The whole experiment was carried out in HPG-250 artificial climate chambers under a photoperiod of 12 h light/12 h dark.

Electric conductance was measured with a electric conductivity meter (Mc26; Japan) as described by Zhang (1989). Relative electrolyte leakage rate and cell membrane damage rate were calculated using three different formulae:

1) exosmosis electric conductance $\left(\mu \mathrm{s} \cdot \mathrm{cm}^{-1} \cdot \mathrm{g}^{-1} \cdot \mathrm{mL}^{-1}\right)=($ treatment conductance - background conductance)/fresh weight $\times$ solution volume

2) relative electrolyte leakage rate $=$ (treatment conductance)/(boiled total conductance) $\times 100 \%$ and

3) cell membrance damage rate $=$ (conductance of treatment - conductance of control)/(boiled total conductance of treatment - conductance of control $) \times 100 \%$

\section{Results and discussion}

Resistance of S. lycopersicoides to CMV. Infection percentage of L. esculentum 'Zaofen No. 2' was 9\%, 37\%, 82\%, and $100 \%$ respectively, with the disease index being $8 \%, 28 \%$, $56 \%$, and $84 \%$ respectively at days $21,28,35$, and 42 after inoculation. However, there were no infection symptoms on the five lines of $S$. lycopersicoides during the whole investigation period (42d). This result indicated that $S$. lycopersicoides was highly resistant to CMV

Resistance of $S$. lycopersicoides to leaf mold. At day 21 after inoculation, the percentage of infected plants of L. esculentum 'Zaofen No. 2' reached $100 \%$ with a disease index of

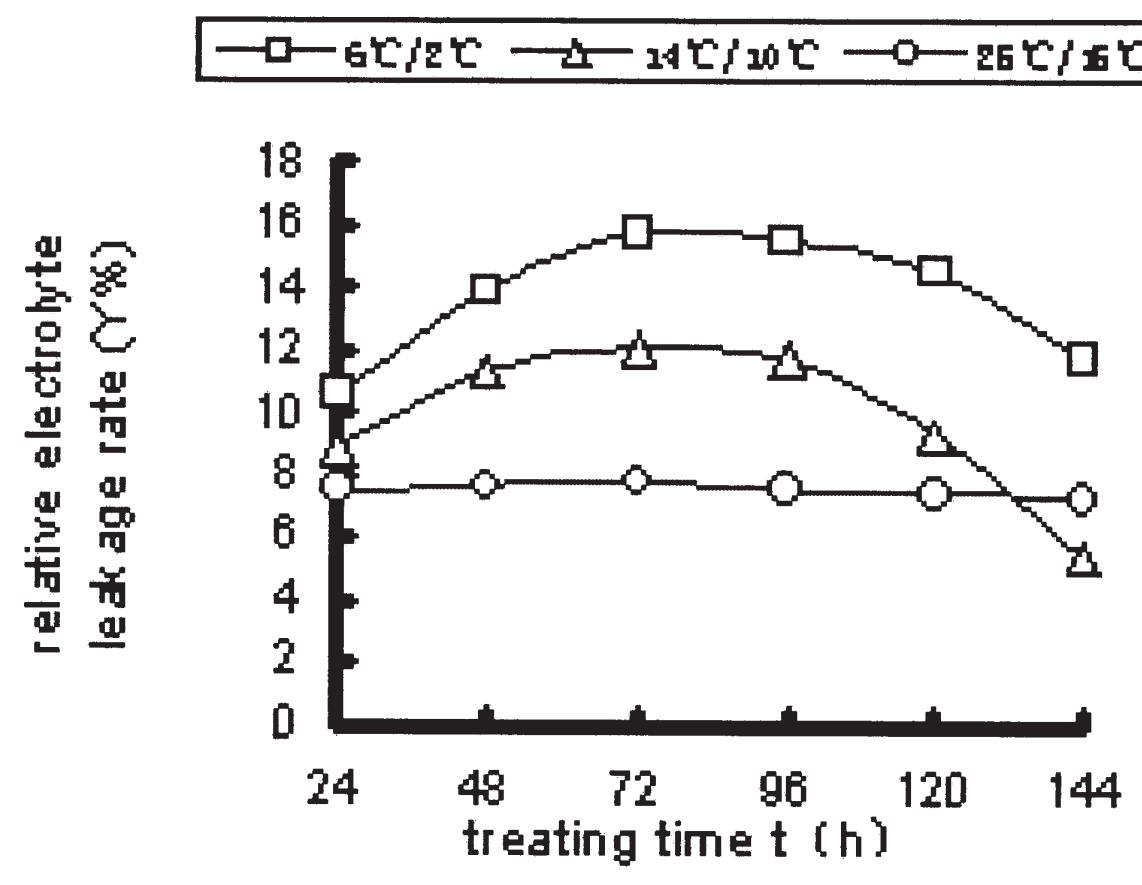

Fig. 1. Changes in relative electrolyte leakage rate by time at different low-termperature levels.
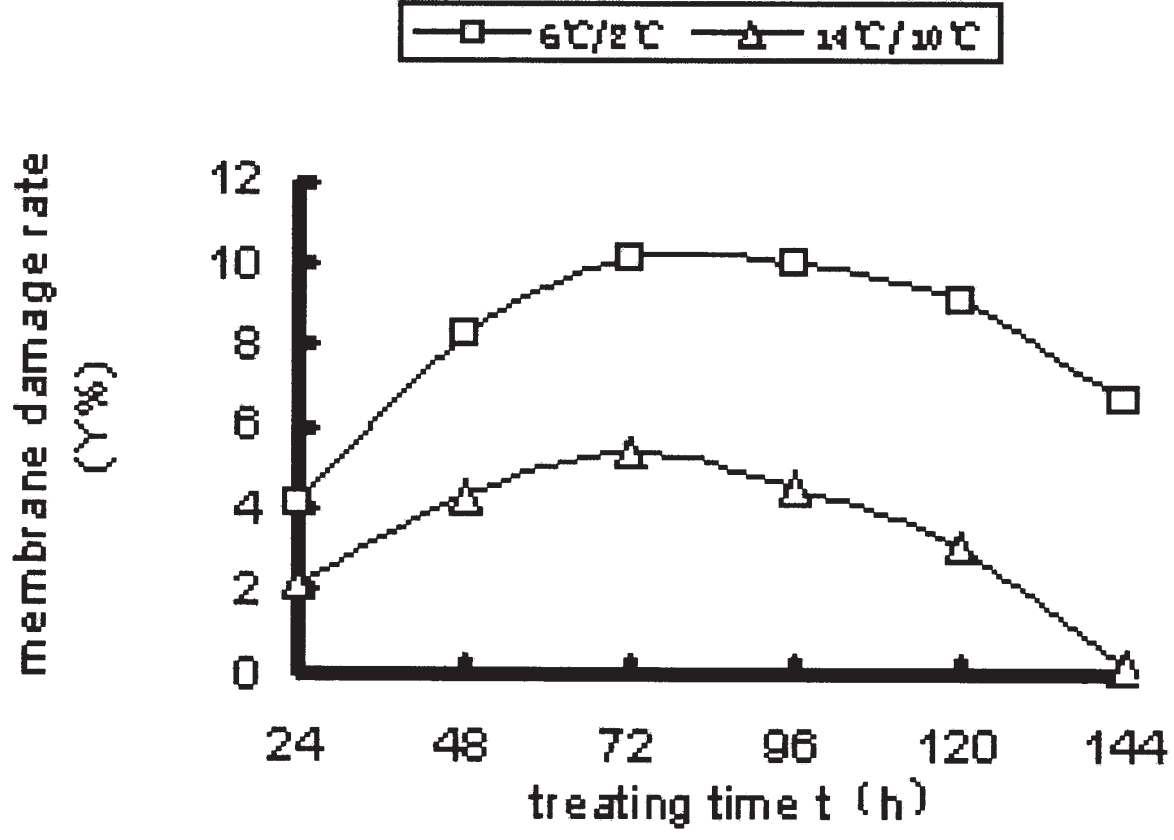

Fig. 2. Changes in membrane damage rate by time at different low-termperature levels. 


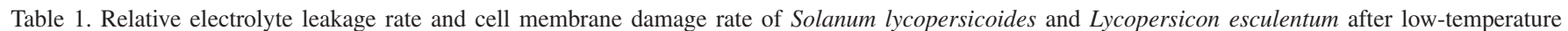
treatment $(72 \mathrm{~h}){ }^{\mathrm{Z}}$

\begin{tabular}{|c|c|c|c|c|c|c|c|c|c|}
\hline \multirow[b]{2}{*}{ Materials } & \multicolumn{6}{|c|}{ Relative electrolyte leakage rate } & \multicolumn{3}{|c|}{ Membrane damage rate } \\
\hline & $6 / 2{ }^{\circ} \mathrm{C}^{\mathrm{y}}$ & $P_{0.01}{ }^{\mathrm{x}}$ & $P_{0.05}$ & $25 / 15^{\circ} \mathrm{C}$ & $P_{0.01}$ & $P_{0.05}$ & $6 / 2{ }^{\circ} \mathrm{C}$ & $P_{0.01}$ & $P_{0.05}$ \\
\hline \multicolumn{10}{|c|}{ S. lycopersicoides } \\
\hline LA1990 & 10.38 & $\mathrm{CD}$ & cde & 7.09 & $\mathrm{BC}$ & $\mathrm{c}$ & 4.81 & $\mathrm{D}$ & $\mathrm{d}$ \\
\hline LA2386 & 10.09 & $\mathrm{CD}$ & de & 8.85 & $\mathrm{AB}$ & $\mathrm{ab}$ & 3.61 & $\mathrm{E}$ & $\mathrm{e}$ \\
\hline LA2730 & 11.79 & $\mathrm{BC}$ & $\mathrm{c}$ & 7.69 & $\mathrm{~B}$ & $\mathrm{bc}$ & 7.19 & $\mathrm{~B}$ & $\mathrm{~b}$ \\
\hline LA2776 & 9.32 & $\mathrm{D}$ & $\mathrm{e}$ & 5.56 & $\mathrm{C}$ & $\mathrm{d}$ & 6.06 & $\mathrm{C}$ & $\mathrm{c}$ \\
\hline LA2951 & 11.00 & $\mathrm{CD}$ & $\mathrm{cd}$ & 8.00 & $\mathrm{~B}$ & bc & 7.38 & $\mathrm{~B}$ & $\mathrm{~b}$ \\
\hline \multicolumn{10}{|l|}{ L. esculentum } \\
\hline $\mathrm{UC} 82 \mathrm{~B}$ & 15.70 & A & $\mathrm{a}$ & 7.81 & $\mathrm{~B}$ & bc & 10.12 & A & $\mathrm{a}$ \\
\hline
\end{tabular}

${ }^{2}$ Each value is average of three replications in this table.

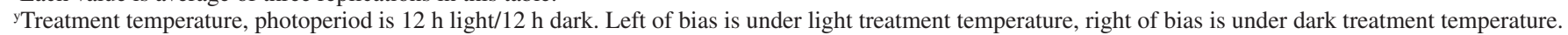
'Duncan's test (SSR), the same capital or small letter indicated no significance at $p=0.01$ or 0.05 .

$89 \%$. No symptoms appeared on the leaves of $S$. lycopersicoides line LA2386, indicating its resistance to leaf mold. The other four S. lycopersicoides lines (LA1990, LA2730, LA2776, and LA2951) showed chlorotic spots, not necrotic, with a $1 \mathrm{~mm}$ diameter on inoculated leaves, which did not increase in severity. The disease index of these four four lines was about $11 \%$, suggesting a substantially high resistance to leaf mold.

Relative electrolyte leakage rate and cell membrane damage rate of 'UC82B' under low temperature stress. Both relative electrolyte leakage rate and cell membrane damage rate of 'UC82B' increased with a decrease temperature. The electrolyte leakage rates of 'UC82BV' began to rapidly increase from $24 \mathrm{~h}$, peaked at about $84 \mathrm{~h}$, and then reduced gradually under treatment at $6 / 2{ }^{\circ} \mathrm{C}$. Those of 'UC82B' showed similar variation tendency (low-high-low), peaking at about $72 \mathrm{~h}$ under $14 / 10^{\circ} \mathrm{C}$. Variation tendency of the electrolyte leakage rates during the whole tested period closely followed a roughly straight line treated under $25 / 15{ }^{\circ} \mathrm{C}$ (Fig. 1), indicating that it is not obviously harmful to tomato at $25 / 15^{\circ} \mathrm{C}$. Therefore, $25 / 15^{\circ} \mathrm{C}$ was used as the nondamaging control for the low-temperature study in tomato. Furthermore, cell membrane damage rate of UC82BV also showed low-high-low variation tendency under treatment at $6 / 2{ }^{\circ} \mathrm{C}$ and $14 / 10{ }^{\circ} \mathrm{C}$ (Fig. 2).

Based on our experimental results, the models for electrolyte leakage rate and cell membrane damage rate under cold treatments were proposed as follows:

$\mathrm{Y}_{\mathrm{E}^{\circ}{ }^{\circ} \mathrm{C} / 2^{\circ} \mathrm{C}}=5.9507+0.2261 \mathrm{t}-1.2963 \mathrm{E}^{-3} \mathrm{t}^{2}(\mathrm{~F}$ $\left.=126.2031^{* *}\right)$

$\mathrm{Y}_{\mathrm{E} 14^{\circ} \mathrm{C} / 10^{\circ} \mathrm{C}}=4.6757+0.2045 \mathrm{t}-1.3861 \mathrm{E}^{-3} \mathrm{t}^{2}$ $\left(\mathrm{F}=302.4729^{* *}\right)$

$\mathrm{Y}_{\mathrm{C} 6{ }^{\circ} \mathrm{C} / 2^{\circ} \mathrm{C}}=0.7516+0.2137 \mathrm{t}-1.2028 \mathrm{E}^{-3} \mathrm{t}^{2}(\mathrm{~F}$ $=98.2094^{* *}$ )

$\mathrm{Y}_{\mathrm{C} 14^{\circ} \mathrm{C} / 10^{\circ} \mathrm{C}}=1.1554+0.1664 \mathrm{t}-1.0943 \mathrm{E}^{-3} \mathrm{t}^{2}$ $\left(\mathrm{F}=79.7454^{* *}\right)$

where $\mathrm{Y}_{\mathrm{E}}$ was relative electrolyte leakage rate, $\mathrm{Y}_{\mathrm{C}}$ was damage rate of cell membrane and $t$ was treatment duration of low temperature.

According to above simulation equations, the time of relative electrolyte leakage rate and cell membrane damage value reaching maximum levels could be calculated, which were 87 and $89 \mathrm{~h}$ respectively in the $6 / 2{ }^{\circ} \mathrm{C}$ treatments, and 74 and $76 \mathrm{~h}$ respectively in $14 / 10{ }^{\circ} \mathrm{C}$ treatments.

Total electrolyte leakage rate was deter- mined at any time point under specific cold treatment condition, which included naturally basal electrolyte leakage (with no stress, or baseline leakage) and cold-induced electrolyte leakage. After naturally basal electrolyte leakage was eliminated, the remained electrolyte leakage rates represented cell membrane damage degree, produced only by low temperature stress.

Furthermore, according to the last two simulation equations above, the time duration that 'UC82B' completely recovered from the damage (the dynamic balance between the tomato active response and the low temperature damage) could be calculated. At $6 / 2{ }^{\circ} \mathrm{C}$ and $14 / 10{ }^{\circ} \mathrm{C}$ treatments, values of $\mathrm{t}_{6{ }^{\circ} \mathrm{C} / 2^{\circ} \mathrm{C}}$ and $\mathrm{t}_{14^{\circ} \mathrm{C} / 10^{\circ} \mathrm{C}}$ were 181 and $145 \mathrm{~h}$ respectively (Fig. 2 ). These results suggested the greater the low temperature stress intensity, the more time is required for tomato to completely recover from the damage. Burr et al. (1990) reported that freeze-induced electrolyte leakage analysis tests were a precise, sensitive, and objective predictor of changes or differences in tissue cold hardiness. Sutinen et al. (1992) successfully estimated freezing stress resistance in winter-hardy red pine needles by combining the electrolyte leakage analysis method with visual observations. Bigras (1997) assessed root cold tolerance of black spruce seedlings using electrolyte leakage analysis as a viability test in relation to survival and regrowth. Campos et al. (2003) compared five Coffea genotypes differing in their sensitivity to low temperatures as well as their ability to recover from cold-induced injury upon rewarming for $6 \mathrm{~d}$, results differing among various genotypes. However, little is known about the time needed for recovery of damaged cell membranes. In the present study, our results provide useful information for studying the relation between cold treatment intensity and recovery time for reversion of cold-induced membrane damage.

As shown in Figs. 1 and 2, the variation tendency of both relative electrolyte leakage rate and cell membrane damage rate varied with the treatment time of ' $U C 82 B$ '. Both peak values appeared at around day 3 to day 4 (75 to $88 \mathrm{~h}$ ) after low temperature treatment. This pattern was consistent with $\mathrm{Ca}^{2+}$ concentration change, gene expression, and vacuole pinocytosis, reflecting shock response of tomato to low temperature stress (Jian, 1999; Wang et al., 1994). Therefore, the $25 / 15^{\circ} \mathrm{C}$ treatment was used as the nonstress control in low temperature tolerance study of $S$. lycopersicoides. At $6 / 2{ }^{\circ} \mathrm{C}$, it was appropriate to use a treatment of $72 \mathrm{~h}$ duration.

Relative electrolyte leakage rate and cell membrane damage rate of S. lycopersicoides under low temperature stress. Relative electrolyte leakage rates of all five lines of S. lycopersicoides ranging from $9 \%$ to $12 \%$ were significantly lower than that of 'UC82B' $(16 \%)$ at $6 / 2{ }^{\circ} \mathrm{C}$ at the $P_{0.01}$ level (Table 1), suggesting that all lines of $S$. lycopersicoides were significantly more cold-tolerant than 'UC82B'. The relative electrolyte leakage rates of $S$. lycopersicoides, however, were not significantly different from that of 'UC82B' at $25 / 15^{\circ} \mathrm{C}$ at the $P_{0.01}$ level, except for LA2776 (Table 1).

In order to further investigate cold tolerance of S. lycopersicoides, cell membrane damage rates of all five lines of $S$. lycopersicoides were measured, and the values ranged from $5 \%$ to $8 \%$, which were significantly lower than that of 'UC82B' (10\%) at the $P_{0.01}$ level (Table 1). These results were consistent with those from the relative electrolyte leakage rate analysis. Therefore, it can be concluded that $S$. lycopersicoides is more cold-tolerant than L. esculentum, implying its potential value as breeding material for improving tomato's cold tolerance. Cold tolerance of $S$. lycopersicoides differed among lines (Table 1), suggesting that much attention should be given in choosing resistant lines of $S$. lycopersicoides to improve cold tolerance of tomato.

In addition to cold tolerance, $S$. lycopersicodes also shows high resistance or immunity to CMV and leaf mold.

\section{Literature Cited}

Bigras, F.J. 1997. Root cold tolerance of black spruce seedlings: Viability tests in relation to survival and regrowth. Tree Physiol. 17:311-318.

Burr, K.E., R.W.Tinus, S.J. Wallner, and R.M. King. 1990. Comparison of three cold hardiness tests for conifer seedlings. Tree Physiol. 6:351-369.

Campos, P.S., V. Quartin, J.C. Ramalho, and M.A. Nunes. 2003. Electrolyte leakage and lipid degradation account for cold sensitivity in leaves of Coffea sp. plants. J. Plant Physiol. 160:283-292.

Chetelat, R.T., C.M. Rick, and J.W. DeVernna. 1989. Isozyme analysis, chromosome pairing, and fertility of L.esculentum $\times$ Solanum lycopersicoides diploid backcross hybrids. Genome 32:783-790.

Chetelat, R.T., P. Cisneros, L. Stamova, and C.M. 
Rick. 1997. A male-fertile L. esculentum $\times$ Solanum lycopersicoides hybrid enables direct backcrossing to tomato at the diploid level. Euphytica 95:99-108.

Chetelat, R.T., C.M. Rick, P. Cisneros, K.B. Alpert, and J.W. DeVernna. 1998. Identification, transmission, and cytological behavior of Solanum lycopersicoides Dun. monosomic alien addition lines in tomato (Lycopersicon esculentum Mill.). Genome 41:40-50.

Chetelat, R.T. and V. Meglic. 2000. Molecular mapping of chromosome segments introgressed from Solanum lycopersicoidesinto cultivated tomato (Lycopersicon esculentum). Theor. Appl. Genet. 100:232-241.

Chetelat, R.T., V. Meglic, and P. Cisneros. 2000. A genetic map of tomato based on BC1 of Lycopersicon esculentum $\times$ Solanum lycopersicoides reveals overall synteny but suppressed recombination between these homeologous genomes. Genetics 154:857-867.

Guri, A., L.J. Dunbar, and K.C. Sink. 1991. Somatic hybridization between selected Lycoperscon and Solanum species. Plant Cell Rpt. 10: 76-80.

Handley, L.W., R.L. Nickeks, M.W. Cameron, P.P. Moore, and K.C. Sink. 1986. Somatic hybrid plant between L. esculentum and Solanum lycopersicoides. Theor. Appl. Genet. 71:691-697.
Hossain, M., S. Imanishi, and A. Matsumoto. 1994. Production of somatic hybrids between tomato (Lycopersicon esculentum) and nightshade (Solanum lycopersicoides) by electrofusion. Breed. Sci. 44:405-412.

Jian, L.C. 1999. A simple summary of 40 years cell biology studies on mechanism of cold resistance in plant. Plant Bul. 16:15-29.

Kamps, T.L., T.G. Isleib, R.C. Herner, and K.C. Sink. 1987. Evaluation of techniques to measure chilling injury in tomato. HortScience 22:1309-1312.

Li, S.D. 1995. Progress in disease resistance breeding in main Chinese vegetables. Science Press, Beijing.

Matsumoto, A., S. Imanishi, M. Hossain, A. Escalante, and H. Egashira. 1997. Fertile somatic hybrids between $\mathrm{F}_{1}$ (Lycopersicon esculentum $\times$ L. peruvianum var. humifusum) and Solanum lycopersicodes. Breed. Sci. 47:327-333.

Rick, C.M. 1951. Hybrids between Lycopersicon esculentum Mill. and Solanum lycopersicoides Dun. Proc. Natl. Acad. Sci. USA 37:741-744.

Rick, C.M. 1986. Germplasm resources in the wild tomato species. Acta Hort. 190:39-47.

Rick, C.M., J.W. Deverna, R.T. Chetelat, and M.A. Stevens. 1986. Meiosis in sesquidiploid hybrids of L. esculentum and Solanum lycopersicoides.
Proc. Natl. Acad. Sci. USA. 83:3580-3583.

Rick, C.M. 1988. Tomato-like nightshades: Affinities, autoecology, and breeders' opportunities. Econ. Bot. 42:145-154.

Rick, C.M. and M. Holle. 1990.Andean Lycopersicon esculentum var. cerasiforme: genetic variation and its evolutionary significance. Econo. Bot. 44(suppl.):69-78.

Rick, C.M. and R.T. Chetelat. 1995. Utilization of related wild species for tomato improvement. Acta Hort. 412:21-38.

Sutinen M.L., J.P. Palta, and P.B. Reich. 1992. Reich Seasonal differences in freezing stress resistance of needles of Pinus nigra and Pinus resinosa: Evaluation of the electrolyte leakage method. Tree Physiol. 11:241-54.

Wang, Y., H.F. Yang, and S.D. Li. 1994. Studies on chilling injury and cold hardiness of horticultural crops. Acta Hort. Sin. 21:239-244.

Wolf, S., D. Yakir, M.A. Stevens, and J. Rudich. 1986. Cold temperature tolerance of wild tomato species. J. Amer. Soc. Hort. Sci. 111:960-964.

Zhang, X. Z. 1989. Techniques of plant physiology. Liaoning Sci. \& Technol Press, Liaoning, China.

Zhang, D.M., X.Y. Yu, Y.H. Jing, and C.H. Wang. 2000. Advance in leaf mold of tomato. J. Zhelimu Animal Husbandry Coll. 2:71-73. 